\title{
RETRATO DA EXPANSÃO E AVALIAÇÃO DOS CURSOS SUPERIORES DE TECNOLOGIA DE 2003 A 2018
}

\author{
PORTRAIT OF EXPANSION AND EVALUATION OF TECHNOLOGICAL HIGHER \\ COURSES FROM 2003 TO 2018
}

\author{
RETRATO DE EXPANSIÓN Y EVALUACIÓN DE CURSOS TECNOLÓGICOS SUPERIORES \\ DE 2003 A 2018
}

José Vieira de Sousa

$(U n B)$

\section{https://doi.org/10.29404/rtps-v5i8.377}

\begin{abstract}
RESUMO: 0 artigo analisa as principais tendências, controvérsias e motivações que explicam a expansão e avaliação dos Cursos Superiores de Tecnologia (CSTs), considerando, por um lado, a flexibilidade apontada pela Lei de Diretrizes e Bases - LDB n ${ }^{0}$ 9.394/96 e, por outro, a política definida para a educação superior brasileira, entre 2003 e 2018. A discussão recorre à literatura que trata do tema e aos dados produzidos pelo Instituto Nacional de Estudos e Pesquisas Educacionais Anísio Teixeira sobre a expansão, avaliação, matrículas e concluintes dos CSTs, no período. $O$ texto analisa a inserção desses cursos na Reforma da Educação Profissional e Tecnológica ocorrida no Brasil, na década de 1990, e das políticas formuladas para o setor. Também examina a relação entre o aumento de sua oferta e a qualidade da formação dos estudantes que os procuram, evidenciando as áreas do conhecimento de maior expressão no processo.
\end{abstract}

Palavras-chave: Educação Profissional e Tecnológica. Curso Superior de Tecnologia. Expansão do Ensino Superior. Avaliação Educacional. Qualidade de Ensino.

ABSTRACT: the article analyzes the main trends, controversies and motivations that explain the expansion and evaluation of Higher Technology Courses (CSTs), considering, on the one hand, the flexibility pointed out by the Law of Guidelines and Bases - LDB n 0.394 / 96 and, on the other, the policy defined for Brazilian higher education, between 2003 and 2018. The discussion uses the literature on the subject and the data produced by the National Institute of Educational Studies and Research Anísio Teixeira on the expansion, evaluation, enrollment and graduates of CSTs, in the period. The text analyzes the insertion of these courses in the Reform of Professional and Technological Education that occurred in Brazil, in the 1990s, and of the policies formulated for the sector. It also examines the relationship between the increase in its offer and the quality of the training of students who seek them, highlighting the areas of knowledge of greater expression in the process.

Keywords: Professional and Technological Education. Higher Technology Course. Expansion of Higher Education. Educational Evaluation. Quality of Teaching.
RESUMEN: El artículo analiza las principales tendencias, controversias y motivaciones que explican la expansión y evaluación de los Cursos de Tecnología Superior (CST), considerando, por un lado, la flexibilidad señalada por la Ley de Directivas y Bases - LDB n 9.394 / 96 y, por otro, la política definida para la educación superior brasileña, entre 2003 y 2018. La discusión utiliza la literatura que trata el tema y los datos producidos por el Instituto Nacional de Estudios e Investigación Educativa Anísio Teixeira sobre la expansión, evaluación, inscripciones y graduados de los CST, en el período. El texto analiza la inserción de estos cursos en la Reforma de la Educación Profesional y Tecnológica que tuvo lugar en Brasil, en la década de 1990, y de las políticas formuladas para el sector. También examina la relación entre el aumento de su oferta y la calidad de la formación de los estudiantes que los buscan, destacando las áreas de conocimiento de mayor expresión en el proceso.

Palabras clave: Educación Profesional y Tecnológica. Curso Superior de Tecnología. Expansión de la Educación Superior. Evaluación Educativa. Calidad de la Enseñanza. 


\section{Considerações iniciais}

Este trabalho tem por objetivo analisar as principais tendências do processo de expansão e avaliação dos Cursos Superiores de Tecnologia (CSTs) ${ }^{1}$, considerando a política formulada para a educação superior e sua articulação com as demandas da sociedade brasileira, no período entre 2003 e 2018. A opção pelo intervalo de quinze anos orienta-se para a identificação de elementos importantes para o exame das repercussões da flexibilização da Lei de Diretrizes e Bases da Educação - LDB n 9.394/96 (BRASIL, 1996) para a diversificação de instituições e cursos superiores, no Brasil, com ênfase na dinâmica assumida pela oferta dos CSTs.

Na sociedade contemporânea, a educação superior é encarada como fator crucial para o desenvolvimento dos projetos políticos dos países, sendo encarado como espaço de luta por parte de diferentes atores, todos interessados em sua dinâmica e funcionamento (SOUSA, 2013). Partindo dessa premissa, a reflexão feita no artigo reconhece que a expressão dos interesses desses atores ocorre em relação a dois subcampos - o público e o privado - os quais se constroem de forma relacional. Expressa, ainda, a conviçção de que, como qualquer outro campo, o educacional e, de forma mais específica, o da educação superior configurase como um espaço no qual os agentes e as instituições universitárias e não universitárias que o compõem possuem interesses distintos, capazes de mobilizá-los para as relações que nele estabelecem.

Nesse contexto interpretativo, é importante compreender a complexidade da educação superior na sociedade contemporânea e, de maneira particular, as características do processo de expansão e avaliação do CSTs, no Brasil, no referido período. Além disso, há o reconhecimento de que o estudo do sistema brasileiro de educação superior demanda uma postura investigativa que ajude no combate ao discurso, muitas vezes, "acentuadamente ideologizado que insiste em tratá-lo como 'único', quando, na verdade, ele revela, em seu interior, uma dinâmica extremamente complexa função da diversidade que o compõe" (SOUSA, 2003, p. 2).

Partimos do pressuposto que, embora os CSTs venham despertando interesse em debates e fóruns acadêmicos, os estudos empíricos a seu respeito mostram-se, ainda, incipientes. Dessa forma, a reflexão realizada no texto justifica-se pela evidência de que existem poucos estudos na literatura especializada que aborde as tendências sobre a expansão e avaliação desses cursos, em um período de tempo mais longo, apesar da expressiva ampliação de sua oferta por instituições de educação superior (IES) públicas e privadas, em todo o território nacional.

\footnotetext{
1 Na Língua Portuguesa, está consagrado o uso de siglas no plural, acrescentando-lhes um "s" minúsculo, ao final delas (BECHARA, 2015). Nesse texto, registraremos Cursos Superiores de Tecnologia como CSTs, Centro Federal de Educação Tecnológica (CEFETs) e Institutos Federais de Educação, Ciência e Tecnologia (IFETs), etc.
} 
Estruturalmente, o artigo está organizado em quatro partes, além das considerações iniciais e finais. A primeira situa os CSTs na Reforma da Educação Profissional e Tecnológica na segunda metade da década de 1990 e seus desdobramentos. A segunda contextualiza esses cursos nos dois mandatos do governo Luiz Inácio Lula da Silva (2003-2006 e 20072010), destacando o papel do Catálogo Nacional das graduações tecnológicas como organizador das áreas dos cursos em questão. A terceira parte discute a expansão dessas graduações no cenário da educação superior brasileira, analisando dados quantitativos referentes ao período entre 2003 e 2018, de maneira articulada à política educacional definida para o setor. A quarta e última parte problematiza os processos de avaliação e regulação dos CSTs, à luz da política do Sistema Nacional de Avaliação da Educação Superior (Sinaes), em vigência no país, desde 2004.

\section{Os CSTs no contexto da reforma da Educação Profissional e Tecnológica}

Devido ao seu recorte temporal, esse artigo não tem como propósito abordar o surgimento dos CSTs, no país, razão pela qual centra sua discussão a partir da década de 1990. Dessa forma, apenas enfatiza que, no Brasil, a origem desses cursos remonta à Reforma Universitária, instituída pela Lei n 5.540, de 28 de novembro de 1968 (FAVRETTO; MORETO, 2013). Surgem como cursos profissionais de curta duração e modelo de ensino superior alternativo ao universitário, com flexibilidade curricular, práticos e rápidos, visando atender as demandas empresariais e de desenvolvimento da época. Entre 1973 e 1975, expandiram-se, chegando a 28 ministrados em 19 IES, sendo a maioria delas universidades e instituições federais. Em 1980, já eram 138, representando um expressivo aumento de $393,0 \%$, em relação a 1975. Em 1988, um total de 53 IES ofertavam CSTs, das quais aproximadamente $60,0 \%$ pertenciam à esfera privada. Nesse mesmo ano, o Decreto Federal no 97.333 autorizou a criação do primeiro Curso Superior de Tecnologia em Hotelaria, ofertado pelo Hotel-Escola SENAC de São Paulo, ocasionando a diversificação da oferta desse tipo de curso. A partir da década de 1980, muitos desses cursos foram extintos no setor público, ampliando sua oferta em instituições privadas, porém nem sempre por vocação, mas visando aumentar o número deles, e sua futura transformação em universidade, segundo o Parecer n 436, do Conselho Nacional de Educação/Câmara de Educação Superior, de 2 de abril de 2001.

Com a LDB no 9.394/1996 ocorreu a reordenação do marco político-educacional brasileiro para o contexto atual, permitindo que os CSTs fossem ofertados, visando garantir a formação geral e profissional dos estudantes, tornando-os aptos a exercerem plenamente sua profissão por meio de uma formação reconhecida legalmente como equiparável aos cursos de graduação. Depreende-se, portanto, que foi com a promulgação dessa lei e com a aprovação de documentos e dispositivos legais dela decorrentes para a educação tecnológica, que esses cursos passaram a ter mais visibilidade na sociedade e, consequentemente, a ser mais valorizados. 
A LDB n 9.394/1996 dedica um capítulo específico à educação profissional, associando-a às diferentes formas de educação, ao trabalho, à ciência e à tecnologia (Art. 39), dentro do título que se refere aos níveis e modalidades de educação e ensino, com ênfase ao desenvolvimento de competências profissionais. Todavia, a lei revela a ausência da expressão Cursos Superiores de Tecnologia (SOUSA, 2013).

Na década de 1990, com a redução das verbas públicas para a educação superior, o Estado veio diminuindo sua responsabilidade com o financiamento e, com isso, passou a estimular o seu processo de privatização. À época, o sistema educacional brasileiro teve reflexos de um panorama mundial de pressão para a ampliação da oferta de vagas em cursos superiores. Como estratégia, o governo buscou fomentar a educação profissional e tecnológica (EPT), na perspectiva de desencadear, naquele momento histórico, um processo de reorganização, reformulação e expansão dos CSTs (TAKAHASHI, 2010).

Em um cenário marcado por novas transformações no mundo do trabalho, em seus dois mandatos (1995-1998 e 1999-2002), o governo Fernando Henrique Cardoso (FHC) promoveu a reformulação da educação superior visando à diversificação de instituições e cursos, passando uma imagem de expansão do acesso e democratização. Nesse contexto, uma grande parte de IES privadas passou a se credenciar como universidades, a partir de processos de fusão, buscando ter autonomia para a criação e extinção de cursos. Em consequência, passou a existir muitas universidades privadas não confessionais (ANDRADE, 2009), o que trouxe diversas consequências para a educação superior do país, em geral, bem como para os CSTs, em particular.

O aumento da oferta desses cursos foi acompanhado de vários instrumentos normativos que caracterizaram a Reforma da Educação Profissional e Tecnológica, em curso desde a segunda metade da década de 1990, em sintonia com a implantação do Sistema Nacional de Educação Tecnológica ${ }^{2}$ Para acompanhar e avaliar a implantação da reforma foi constituído um Grupo de Trabalho, por meio da Portaria Ministerial n 646, de 14 de maio de 1997, que normatizou a necessidade de as instituições federais de educação tecnológica elaborarem um plano de trabalho. Nesse contexto, foi implementado o Programa Reforma da Educação Profissional (PROEP), por meio da Portaria Ministerial $n^{\circ}$ 1.005, de 10 de setembro de 1997.

De acordo com Souza (2012), no conjunto dos desdobramentos da referida reforma, o primeiro documento a tratar diretamente dos CSTs foi o Parecer CNE/CES n 436/2001 (BRASIL, 2001) que, além de analisar a trajetória dos cursos de curta duração: 1) indicou as

\footnotetext{
2 O Sistema Nacional de Educação Tecnológica foi instituído pela Lei no 8.948, de 8 de dezembro de 1994, visando favorecer a articulação da educação tecnológica em seus vários níveis e entre suas várias instituições $\left(\operatorname{art.} 1^{\circ}, \int 2^{\circ}\right)$. Ele marcou o processo de transformação gradativa das antigas Escolas Técnicas em Centros Federais de Educação (CEFETs), cuja finalidade era formar e qualificar profissionais para atender às tendências dos setores produtivos e da sociedade, por meio de pesquisas e desenvolvimento tecnológico de novos produtos, processos e serviços.
} 
primeiras diretrizes sobre esses cursos; 2) regulamenta sua oferta; 3) identificou as áreas profissionais; 4) estabeleceu as cargas horárias mínimas para as diferentes áreas no intervalo de 1.600 a 2.400 horas; 5) mencionou sua implementação por IES de distintos formatos acadêmicos. Também à época, apesar de algumas polêmicas, o CNE definiu os CSTs como cursos de graduação, com características especiais e bem diferentes dos tradicionais. Todavia, o acesso a eles deveria assemelhar-se ao processo seletivo realizado pelos demais cursos de graduação ${ }^{3}$. O colegiado determinou, ainda, a possibilidade de acesso a qualquer curso de pós-graduação, o que se justifica, segundo Takahashi e Amorim (2008), porque os CSTs são enquadrados no disposto no Inciso II, do art. 44 da LDB/1996, que regulamenta a educação superior no Brasil.

\begin{abstract}
A justificativa recorrente para criação de cursos superiores de tecnologia se baseia em dois argumentos principais. Um é o da necessidade de cursos superiores com duração mais reduzida para atender ao interesse da juventude em dispor de credencial para o mercado de trabalho em tempo mais reduzido; outro é o de que esse tipo de curso permitiria maior rapidez no atendimento às mutações do mercado, ao mesmo tempo em que permite maior aprofundamento em áreas profissionais específicas, em sintonia com o mundo do trabalho (SOUZA; VEIGA, 2020, p. 463).
\end{abstract}

Na primeira metade de década de 2000, os expressivos percentuais de crescimento do CSTs ocorreram especialmente no âmbito do setor privado (FAVRETTO; MORETTO (2013), devido à ampliação das possibilidades de oferta de educação profissional de nível tecnológico, prevista pela referida lei. Na prática, foi ampliada na educação superior a presença de pessoas jurídicas com fins lucrativos, fazendo com que o setor privado visse nesses cursos uma grande oportunidade de negócio, o que se intensificou ao longo do período abordado nesse texto.

Por outro lado, em 2002, foram instituídas as Diretrizes Curriculares Nacionais (DCNs) para a Educação Profissional de Nível Tecnológico, por meio da Resolução CNE/CP no 3/2002 (BRASIL, 2002). Isto ocorreu após o CNE aprofundar o debate da proposta elaborada pela então Secretaria de Educação Média e Tecnológica (SEMTEC) do Ministério da Educação (MEC), que apresentou um quadro de áreas profissionais e cargas horárias mínimas, por meio de documento encaminhado àquele colegiado para deliberação e aprofundamento da discussão. Em seu artigo 15, a referida Resolução fixou que o colegiado promoveria a avaliação de políticas públicas para a implantação dos CSTs até o prazo de dois anos, contados da data de sua vigência.

Em abril de 2004, a Secretaria de Educação Média e Tecnológica (SEMTEC) passou a ser denominada Secretaria de Educação Tecnológica (SETEC). No mesmo ano, houve reestruturação no $\mathrm{MEC}$, separando a política do ensino médio da política da educação profissional, transferindo a primeira para a Secretaria de Educação Básica (SEB).

${ }^{3}$ O processo seletivo dos CSTs foi regulamentado pelos Pareceres CNE/CP n ${ }^{\circ} 95$, de 6 de julho de 1999 e n ${ }^{\circ} 98$, de 28 de janeiro de 1999 . 


\section{Contextualização dos CSTs na expansão da educação superior brasileira}

Nos dois mandatos do governo Luiz Inácio Lula da Silva (2003-2006 e 2007-2010), o aumento do número de matrículas nos cursos de graduação, em geral, e nos CSTs, em particular, está associado, dentre outros, aos seguintes fatores: (i) a reconfiguração do campo da educação superior, sobretudo pós LDB/1996; (ii) os esforços governamentais em definir diretrizes e regulamentar os cursos.

Em relação ao segundo fator, merecem destaque algumas medidas tomadas pelo governo, as quais apresentaram referências importantes para a compreensão de suas influências sobre o aumento de matrículas na graduação. Uma delas refere-se aos efeitos do Decreto S/N, de 20 de outubro de 2003 (BRASIL, 2003), que criou o Grupo de Trabalho Interministerial (GTI), com o objetivo de analisar a situação da educação superior brasileira e apresentar um plano de ação para reestruturação, o desenvolvimento e a democratização das Instituições Federais de Ensino Superior (IFES). No mesmo ano, foi lançado o Programa de Expansão das IFES, visando expandir e interiorizar as universidades federais, levando desenvolvimento econômico e social para os municípios do interior dos estados.

No que tange aos CSTs, no início do primeiro mandato do governo Lula, a EPT enfrentou muitos desafios, o que levou o MEC a formular, em 2004, o documento "Políticas Públicas para a Educação Profissional e Tecnológica", que apontava, dentre outras dificuldades: (i) necessidade de promover a reformulação dos instrumentos legais em curso, de acordo com as diretrizes fixadas pelo governo, inclusive em relação a recursos financeiros definidos e organizados sob a forma de um Fundo Nacional de Desenvolvimento da EPT; (ii) integração de todos os níveis e modalidades de EPT, no ensino formal ou não-formal, envolvendo as instituições que compõem as redes de EPT; (iii) urgência na criação de um Subsistema Nacional de Educação Profissional e Tecnológica, subordinado ao Sistema Nacional de Educação, em condições de articular as várias redes existentes; (iv) necessidade de promover a melhoria da formação de docentes (MEC, 2004).

Outras ações relevantes que podem explicar o expressivo crescimento das matrículas nos CSTs, no primeiro mandato do governo Lula foram: (i) instituição do Programa Universidade para Todos (ProUni), regulamentado pela Medida Provisória n²13, de 10 de setembro de 2004 e institucionalizado pela Lei $\mathrm{n}^{\circ}$ 11.096, de 13 de janeiro de 2005; (ii) implementação do Programa Expandir, no ano de 2006, com o início da expansão das universidades federais.

Paralelamente às ações governamentais desse porte, grupos sociais diversos interessados na EPT se organizaram visando discutir seus rumos. Assim, em novembro de 2006, foi realizada a I Conferência Nacional da Educação Profissional e Tecnológica, em Brasília, que se caracterizou como um espaço de discussão e reflexão dos resultados da reforma da EPT e contou com a participação de representações estaduais de instituições públicas e privadas. 
Na mesma direção, em 2007, foi produzida a Carta de Gramado/RS pelo Conselho Nacional de Dirigentes das Escolas Técnicas vinculadas às Universidades Federais (CONDETUF). Sinteticamente, o documento expressava determinado nível de descontentamento e a necessidade de ampliar o debate de como vinha ocorrendo a expansão da EPT. Porém, na contramão desse pensamento já tinha vindo a Confederação Nacional da Indústria (CNI) que, durante o debate da reforma da educação superior proposta pelo governo Lula, em 2004, manifestara a ideia de que esse nível educacional precisava atender à indústria de forma mais direcionada, por meio de cursos superiores formadores de tecnólogos. (CNI, 2004).

Também cabe citar a criação do Plano de Desenvolvimento da Educação/PDE (2007) que, ao tratar da EPT, enfatiza a criação dos Institutos Federais de Educação, Ciência e Tecnologia (IFETs) como "modelos de reorganização das instituições federais de educação profissional e tecnológica para uma atuação integrada e referenciada regionalmente" (BRASIL, 2007, p. 32).

Em 2008, houve alteração em dispositivos da LDB no 9.394/1996, com vistas a redimensionar, institucionalizar e articular as ações da EPT. Isso ocorreu com a promulgação da Lei $n^{\circ} 11.741$, de 16 de julho de 2008, que alterou o capítulo III do título $\checkmark$ da referida LDB para "Da Educação Profissional e Tecnológica" e atualizou as nomenclaturas dos cursos e programas de Educação Profissional ${ }^{431}$ : "educação profissional de nível tecnológico" foi denominada "educação profissional tecnológica de graduação e pós-graduação" (BRASIL, 2008a). Além disso, promoveu alterações na educação profissional técnica de nível médio e acrescentou um novo parágrafo para tratar da educação profissional de jovens e adultos. Paralelamente a essas expressivas mudanças, ocorreu a transformação dos CEFETs em IFETs, o que foi formalizado pela Lei $\mathrm{n}^{\circ}$ 11.892/2008 (BRASIL, 2008b), constituindo exceções, nesse processo, as unidades instaladas no Rio de Janeiro e em Minas Gerais.

\footnotetext{
O Instituto Federal é, hoje, mais que um novo modelo institucional, é a expressão maior da atual política pública de educação profissional brasileira. Está produzindo mudanças altamente significativas na vida e na história das instituições que optaram por aderir à proposta governamental, por esses motivos essas mudanças precisam ser acompanhadas bem de perto (OTRANTO, 2010, p. 105-106).
}

Analisando o cenário da EPT, no final de década de 2000, Souza (2012) afirma que os CSTs não ganharam o mesmo destaque quando houve a transformação dos IFETs, visto que pelo menos 50,0\% das vagas ofertadas neles tinham que ser destinadas à educação profissional de nível médio. "De qualquer forma, o investimento do governo federal nos

\footnotetext{
${ }^{4}$ De acordo com a Lei no 11.741/2008, a educação profissional de nível básico foi denominada "formação inicial e continuada de trabalhadores" (Inciso I) e, posteriormente, teve acrescentada a expressão “qualificação profissional” pelo Decreto n ${ }^{\circ} 8.268$, de 18 de julho de 2014. Por sua vez, a educação Profissional de nível técnico foi denominada "educação profissional técnica de nível médio" (Inciso II).
} 
CSTs valoriza, impulsiona essa modalidade, fazendo que seus profissionais sejam mais aceitos no mercado de trabalho" (SOUZA, 2012, p. 91). Além disso, foi estabelecido que esses institutos deveriam garantir o mínimo de $20,0 \%$ de suas vagas aos cursos de licenciatura e programas especiais de formação pedagógica. O propósito desses programas envolve a formação de professores para a educação básica, principalmente para a Educação Profissional e Tecnológica, bem como para as áreas de Ciências e Matemática.

Domingos Sobrinho (2007) critica o conjunto de mudanças para os IFETs, considerando que grande parte dessas instituições ainda não conseguira perceber claramente sua nova identidade, até porque sua concepção é totalmente nova na história da educação brasileira. Fica subjacente à crítica do autor a ideia de que vários desses institutos deixaram de ser colégios e se tornaram instituições universitárias, mas instituições diferenciadas e bem heterogêneas, se comparadas com as universidades federais. Conclusões como essa são recorrentes na literatura que trata da temática, revelando que a mudança de uma nova estrutura - de escola para instituto - trouxe atribuições formais que ainda não são bem compreendidas na prática pelos gestores, o que se mostra associado, dentre outros, às dimensões do planejamento e da formação. Nessa direção, Otranto (2010, p. 106) alerta para a necessidade de, em relação aos IFETs, em última análise, "investigar se as promessas estão sendo cumpridas, para que se possa avaliar se, realmente, a atual política tem condições de contribuir para a expansão, com qualidade socialmente referenciada, da educação profissional brasileira".

Devido à sua importância para a expansão da educação superior nas duas últimas décadas, os CSTs passaram a demandar do Estado a formulação de ações governamentais, sendo uma delas a elaboração do Catálogo Nacional de Cursos Superiores de Tecnologia, em 2006. Em sua $1^{a}$ edição, já apresentava as denominações dos cursos, o perfil profissiográfico para cada CST, carga horária mínima e infraestrutura recomendada formalizada como nova competência da SETEC, a partir do Decreto $n^{\circ} 5.773$, de 9 de maio de 2006. Finalizado o documento, que teve a adequação da denominação dos cursos regulamentada pela Portaria Ministerial $n^{\circ} 12$, de 14 de agosto de 2006, passou por novas inclusões. ${ }^{5}$ Definiu a oferta de CSTs em três categorias: Tecnologias Simbólicas, Tecnologias Físicas e Tecnologias Organizacionais, conforme apresenta o Parecer CNE/CES n 277, de 7 de dezembro de 2006. Essas categorias organizaram-se em torno de conjuntos compactos de Eixos Tecnológicos flexíveis: 1) Ambiente, Saúde e Segurança; 2) Controle e Processos Industriais; 3) Gestão e Negócios; 4) Hospitalidade e Lazer; 5) Informação e Comunicação; 6) Infraestrutura; 7) Produção Alimentícia; 8) Produção Cultural e Design; 9) Produção Industrial; 10) Recursos Naturais.

Por meio da SETEC, o MEC atualizou o catálogo em 2010, publicando sua $2^{\mathrm{a}}$ edição, cujo objetivo era ser um guia de referência para "estudantes, educadores, instituições

\footnotetext{
${ }^{5}$ O Curso Superior em Processos Ambientais e o Curso Superior de Tecnologia Oftálmica foram incluídos no Catálogo por meio da Portaria n ${ }^{\circ} 282$, de 29 de dezembro de 2006.
} 
ofertantes, sistemas e redes de ensino, entidades representativas de classes, empregadores e o público em geral" (BRASIL, 2010, p. 8). O documento apresentou denominações, perfil do egresso, carga horária mínima e infraestrutura recomendada para 112 graduações tecnológicas organizadas em 13 eixos. Uma nova atualização do catálogo, gerando sua $3^{a}$ edição, foi instituída pela Portaria No 413, de 11 de maio de 2016, mantendo a quantidade de graduações e eixos (BRASIL, 2016).

Com efeito, ainda que o catálogo tenha contribuído para a organização dos CSTs, determinadas limitações do mercado de trabalho relacionadas a esses cursos continuam a ser apontadas pela literatura especializada, considerando, dentre outros elementos, o perfil discente e determinadas diferenças relativas à sua oferta pelas IES públicas e privadas. Estudos como o de Machado e Mesquita (2013) caracterizam o perfil de estudantes dos CSTs como pessoas que possuem majoritariamente idade entre 18 e 30 anos, buscando se inserir em áreas tecnológicas das diversas áreas. Expressiva parte dessas pessoas tem atuação profissional nas áreas afins ao curso ou em área diversa e revela a pretensão de realizar a capacitação para ter outras oportunidades no mercado de trabalho. Apontam, ainda, que a oferta desses cursos pela rede privada apresenta a tendência de atender às demandas de mercado, pautada em pesquisas de marketing, o que garante a competitividade do setor. Em contrapartida, os da rede pública são, por vezes, voltados a uma educação com ligação ao desenvolvimento sustentável e regional.

\section{A expansão dos CSTs no Brasil: o que dizem os números?}

Considerando o exposto nas seções anteriores, a Tabela 1, apresentada a seguir, expõe dados sobre a evolução dos cursos de graduação no Brasil, em todas as suas modalidades, e dos CSTs, em particular, no período entre 2003 e 2018, recorte temporal explorado nesse artigo. Em seu conjunto, os dados mostram um significativo crescimento do número de cursos de graduação, considerando o conjunto de IES públicas e privadas que os ofertam, considerando que, em 2003, havia 16.438 cursos e, em 2018, esse número passa a ser de 37.962, representando um expressivo aumento de 130,9\%. Todavia, a análise da variação dessa expansão nas duas metades do período revela que nelas houve também um aumento bastante grande - de 2003 a 2009 (69,3\%) e 2010 e 2018 (54,9\%).

Os dados da tabela permitem também verificar que, tal como na graduação em geral, houve o mesmo movimento expansionista, em relação aos CSTs. De maneira mais objetiva, mostram que esses cursos cresceram de forma rápida, ao longo de toda a série histórica analisada. Todavia, particularmente, durante os dois mandatos do governo Lula (2003-2007 e 2008-2010), eles aumentaram de maneira mais expressiva (42,5\%), visto que passaram de 1.142 para 4.999, no período. Ainda que o governo seguinte - primeiro mandato da presidenta Dilma Rousseff (2011-2014) - tenha continuado a incentivar a oferta dos CSTs, sua expansão ficou em $17,0 \%$, visto que passaram de 5.478 para 6.413 , nesse segundo momento do período examinado. Quanto ao interstício 2015-2018, nele o aumento desses 
cursos foi praticamente o mesmo do anteriormente analisado (18,0\%), pois de 6.618 chegou a um total de 7.810 .

Tabela 1 - Evolução do nº de cursos de graduação e CSTs no Brasil (2003-2018)

\begin{tabular}{ccccc}
\hline Ano & $\begin{array}{c}\text { Graduação em } \\
\text { geral }\end{array}$ & $\begin{array}{c}\text { Variação da } \\
\text { graduação em } \\
\text { geral }\end{array}$ & CSTs & Variação CSTs \\
\hline 2003 & 16.438 & ----- & 1.142 & ----- \\
2004 & 18.644 & $13,4 \%$ & 1.804 & $58,0 \%$ \\
2005 & 20.407 & $9,5 \%$ & 2.525 & $40,0 \%$ \\
2006 & 22.101 & $8,3 \%$ & 3.037 & $20,3 \%$ \\
2007 & 23.488 & $6,3 \%$ & 3.702 & $21,9 \%$ \\
2008 & 24.719 & $5,2 \%$ & 4.355 & $17,6 \%$ \\
2009 & 27.827 & $12,6 \%$ & 4.691 & $7,7 \%$ \\
2010 & 24.508 & $-11,9 \%$ & 4.999 & $6,6 \%$ \\
2011 & 24.942 & $1,8 \%$ & 5.478 & $9,6 \%$ \\
2012 & 25.897 & $3,8 \%$ & 5.969 & $9,0 \%$ \\
2013 & 30.791 & $18,9 \%$ & 6.363 & $6,6 \%$ \\
2014 & 32.878 & $6,8 \%$ & 6.413 & $0,8 \%$ \\
2015 & 33.501 & $1,9 \%$ & 6.618 & $3,2 \%$ \\
2016 & 34.366 & $2,6 \%$ & 6.828 & $3,1 \%$ \\
2017 & 35.380 & $3,0 \%$ & 7.005 & $2,6 \%$ \\
2018 & 37.962 & $7,3 \%$ & 7.810 & $11,5 \%$ \\
\hline
\end{tabular}

Fonte: INEP, Microdados do Censo da Educação Superior e Resumos Técnicos - 2003-2018.

É possível constatar, ainda, que o crescimento dos CSTs em determinados interstícios do período retratado na tabela ocorreu em proporções menores, pois em 2011 foi 9,6\%, em relação ao ano de 2010. Nos anos seguintes, decresceu o número das graduações tecnológicas, considerando que em 2014 sua evolução foi de apenas $0,8 \%$, em comparação com 2013.

Destaca-se, também, que, em 2018, o crescimento do número dos CSTs atinge o seu ápice (11,5\%), superando a expansão ocorrida nos cursos de graduação em geral, no país (7,3\%). Esse aumento significativo do número de cursos tecnológicos ocorreu em decorrência de alguns fatos importantes, destacando-se: (i) reforma da educação profissional e tecnológica, ocorrida nos anos 1990; (ii) instituição, ainda em 2002, das DCNs para a EPT, que orientou a organização e o funcionamento desses cursos; (iii) criação do Catálogo Nacional de CSTs, em 2006, e suas atualizações ocorridas em 2010 e 2016; (iv) promulgação da Lei no 13.005/2014, que aprovou o Plano Nacional de Educação (20142024), o qual prevê, em sua Meta 10: "Oferecer, no mínimo, 25\% (vinte e cinco por cento) 
das matrículas de educação de jovens e adultos, nos ensinos fundamental e médio, na forma integrada à educação profissional." (BRASIL, 2014).

Apesar de ainda pequena, se comparada ao universo de cursos superiores de graduação tradicional, a oferta dos CSTs tem sido legitimada nos últimos anos pela regulamentação do MEC e pela sua crescente aceitação social, fatos que corroboram para explicar sua expansão. Com efeito, a organização dessa modalidade trouxe novas perspectivas de ingresso à educação superior no Brasil e, consequentemente, para ampliar as taxas que indicam sua escolarização, que são de duas naturezas - bruta e líquida.

As taxas de escolarização são calculadas utilizando-se exclusivamente dados da PNAD [Pesquisa Nacional por Amostra de Domicílios]. A taxa de escolarização bruta expressa o percentual da população de 18 a 24 anos que declara frequentar escola. A taxa de escolarização líquida, por sua vez, identifica o percentual da população de 18 a 24 anos que declara cursar graduação. (INEP, 2013, p. 50).

Em 2012, o MEC e o INEP empreenderam esforços visando construir uma projeção das taxas de escolarização líquida e bruta de educação superior que o Brasil deveria alcançar, nos anos seguintes, para ter êxito nas metas definidas pelo PNE 2014-2024, como mostrado a seguir.

\section{Gráfico 1 - Projeção de taxas de escolarização na educação superior brasileira (2012- 2022)}

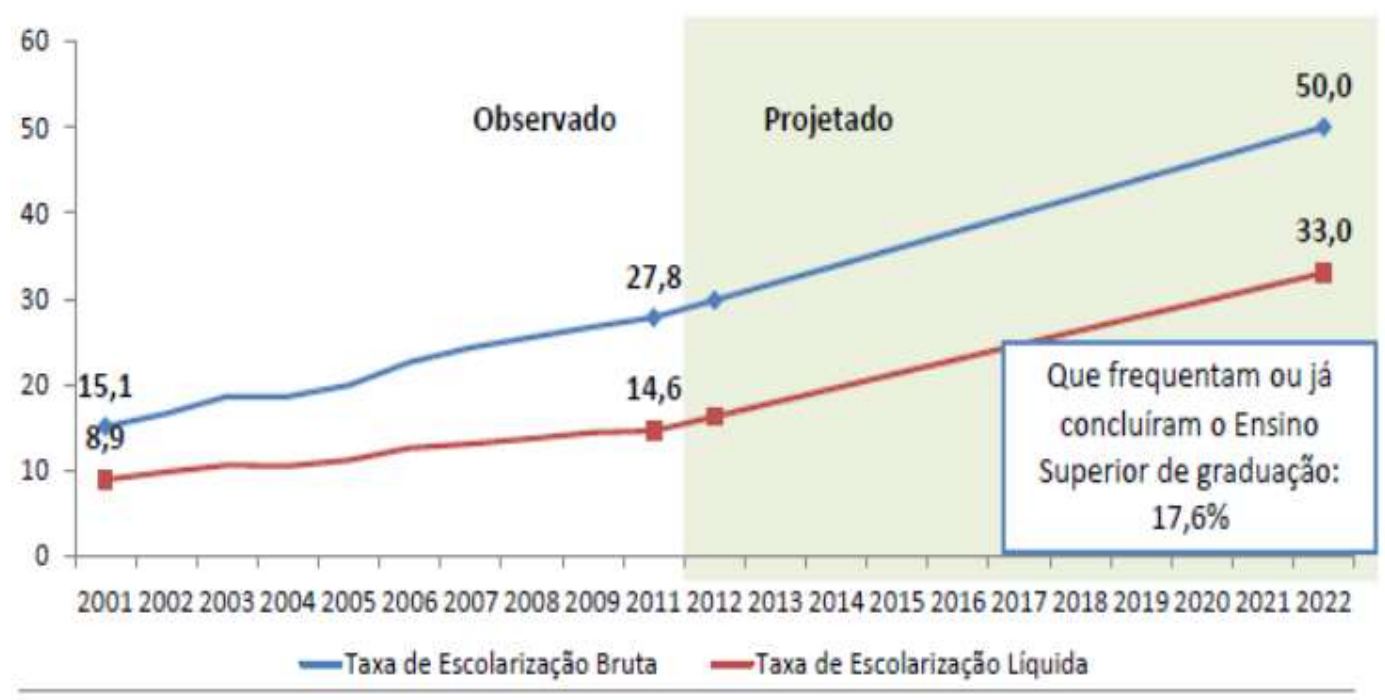

Fonte: MEC/INEP/DEED (2013).

O referido Plano estabelece as duas taxas mostradas no gráfico nos seguintes termos: "Meta 12: Elevar a taxa bruta de matrícula na educação superior para 50\% e a taxa líquida para $33 \%$ da população de 18 a 24 anos, assegurando a qualidade da oferta e expansão 
para, pelo menos, $40 \%$ (quarenta por cento) das novas matrículas, no segmento público" (BRASIL, 2014).

Todavia, em 2018, seis anos para o fim da vigência do PNE 2014-2024, as taxas de escolarização bruta e líquida chegaram, respectivamente, a 37,4\% e 21,7\% (INEP, 2019), indicando que o país ainda precisa enfrentar muitos desafios na expansão da educação superior. Na realidade, quando fez a projeção das taxas em questão, o poder público já presumia que "esses dados corroboram o caráter desafiador do salto projetado pela Meta 12" (INEP, 2013, p. 50).

Os dados atestam que, apesar dos avanços obtidos, o Brasil continua a se caracterizar como um país cujas taxas de escolarização na educação superior continuam extremamente baixas, notadamente quando comparadas à realidade da América Latina e a de outros países de diferentes regiões do mundo, o que tem sido reiterado nas últimas décadas.

\begin{abstract}
Enquanto, em diversos países, as taxas de escolarização bruta, em geral, são maiores que 50\%, chegando a, por exemplo, 52\% no Chile, 64\% no Uruguai, 56\% na França, e 82\% nos Estados Unidos, no Brasil era de apenas $25 \%$ em 2008 . Em relação aos próprios objetivos estabelecidos pelo Plano Nacional de Educação, o Brasil ainda está muito aquém da meta da taxa de escolarização líquida de 30\% para a educação superior em 2010. Na média geral do país, a taxa estava próxima a 15\% em 2010 (BERTOLIN, 2011, p. 483).
\end{abstract}

Em um cenário desafiador como esse, os CSTs têm contribuído para a ampliação do acesso à educação superior, ainda que em relação a eles recaiam críticas de naturezas diversas, como, por exemplo, o aligeiramento da formação, devido a possuir uma curta duração.

Tabela 2 - Distribuição de matrículas em CSTs, por categoria
administrativa e modalidade de educação (Brasil, 2018)

\begin{tabular}{lrrr}
\hline \multicolumn{1}{c}{ Categoria } & \multicolumn{2}{c}{ Modalidades } & \\
\cline { 2 - 3 } Administrativa & Presencial & A distância & \multicolumn{1}{c}{ Total } \\
\hline Privada & 377.145 & 552.395 & 929.540 \\
Municipal & 2.258 & 210 & 2.468 \\
Estadual & 80.854 & 7.896 & 88.750 \\
Federal & 68.936 & 8.372 & 77.308 \\
\hline
\end{tabular}

Fonte: INEP (2019)

Em 2018, o número de matrículas em graduações tecnológicas chegou a 1.098.066. Desse total, 568.873 (51,8\%) eram ofertadas na modalidade a distância e 529.193 na presencial $(48,2 \%)$. Conforme dados oficiais, no mesmo ano, houve o aumento de $9,9 \%$ no número de matrículas nos CSTs, em relação a 2017, "ocasionado exclusivamente pelos cursos a distância. Pela primeira vez, na série histórica [2008-2018], o número de alunos matriculados, em cursos EaD, supera o número de alunos dos cursos presenciais" (INEP, 2019, p. 40). 
No que tange à natureza administrativa das IES que ofertavam os CSTs, em 2018, um total de 929.540 matrículas (84,7\%) encontravam-se na rede privada, enquanto 168.526 $(15,3 \%)$ pertenciam aos estabelecimentos públicos (INEP, 2019).

Cruzando os dados relativos à oferta desses cursos nas modalidades presencial e a distância com a categoria administrativa das instituições, constata-se que, no referido ano, o total de 1.098 .066 de matrículas desses cursos, distribuía-se conforme mostrado anteriormente.

Os dados da tabela tornam razoável supor que a sociedade tem dado respostas ao crescimento da oferta por meio da rápida absorção do tecnólogo no mercado de trabalho. Mostram, ainda, que a expansão dos CSTs reflete o cenário social, marcado pela acirrada competitividade e pela reestruturação produtiva do capital, frente às novas exigências impostas à educação superior, que precisa atender às demandas do mercado.

\section{Característica dos processos de avaliação e regulação dos CSTs}

No marco do Sistema Nacional de Avaliação da Educação Superior (Sinaes), a avaliação de cursos de graduação se faz, desde 2004, com o objetivo de identificar as condições de ensino oferecidas aos estudantes, em especial as relativas ao perfil do corpo docente, às instalações físicas e à organização didático-pedagógica, mediante o uso de procedimentos e instrumentos variados (BRASIL, 2004). Nesse sistema, a avaliação dos CSTs para fins de autorização, reconhecimento e renovação de reconhecimento integra a regulamentação padrão para os demais cursos de graduação no Brasil. Isso revela a centralidade da avaliação também em relação a esses cursos, pois eles compartilham com os demais de graduação o mesmo processo avaliativo.

No que se refere às avaliações externas dos CSTs presenciais e a distância, a Portaria Normativa INEP $n^{\circ} 31$, de 31 de fevereiro de 2005, estabeleceu os procedimentos para sua organização e execução. Em 2008, por meio de outra Portaria - a de n 3, de 1 de abril de 2008 - alguns CSTs inauguraram a participação de discentes no Exame Nacional de Desempenho dos Estudantes (Enade), componente curricular obrigatório para cursos de graduação do país. Além disso, três anos depois, a regulação e a supervisão deles tornaramse competências da Seres tanto na modalidade presencial como a distância.

Com efeito, ainda é novo o formato no qual insere a educação tecnológica em um modelo de educação superior validada por marcos regulatórios. Para Takahashi e Amorim (2008), tal fato causa desconfiança e até mesmo dificuldade de clareza sobre o melhor caminho a ser seguido pelos CSTs, no que tange à sua avaliação e, consequentemente, à regulação.

Em certo sentido, a equiparação dos cursos de graduação no processo avaliativo pelo Estado é questionada por atores que lidam diretamente com os CSTs. A desconsideração do contexto no qual esses cursos são realizados, as diferenças institucionais e peculiaridades implicadas no processo de criação e o funcionamento deles implicam 
assumir determinadas atribuições que pesam na dinâmica de trabalho das IES que os ofertam. Diante disso, torna-se necessária uma avaliação que considere o que é singular nos CSTs, adotando um instrumento específico de avaliação de cursos para fins de regulação nacional deles. A proposição de um instrumento que garanta as singularidades ganha força na perspectiva de melhor apreender a natureza e organização didáticopedagógica dos cursos em análise.

A preocupação com os resultados da avaliação de cursos mediante conceitos que variam de 1 a 5 mobiliza as ações institucionais em nome da qualidade mínima necessária ao reconhecimento social deles na sociedade. Nesse cenário, é razoável supor que, mesmo não concordando com os procedimentos e instrumentos avaliativos aos quais se submetem as IES tendem a fazem cumprir as exigências porque o impacto da regulação via resultado da avaliação pode implicar situações não desejadas por elas, notadamente para o crescimento dos CSTs.

No contexto da avaliação, tanto os CSTs como os demais de graduação lidam com questões basilares que possuem forte consonância com os condicionantes econômicos e políticos de cada momento histórico. Além disso, é a demanda do mercado de trabalho que influencia quais áreas de conhecimento serão privilegiadas para a abertura ou manutenção deles e não propriamente os resultados obtidos nas avaliações (SOUSA, 2019). Isso pode contribuir para que sejam ofertados em determinadas áreas de conhecimento, buscando perceber qual é a demanda do mercado. Diante disso, tudo indica que a avaliação realizada pelo Sinaes acaba não abarcando as especificidades dos CSTs e que, possivelmente, a regulação dela decorrente fique comprometida.

Considerando a complexidade inerente a todo processo avaliativo, observa-se que aquele realizado pelo Sinaes, com ênfase em seu componente Enade, lida com grandes dilemas, tendo em vista o sistema heterogêneo e diversificado de IES públicas e privadas que o compõem. Um deles é o fato de esse sistema ser operacionalizado em um terreno no qual o que move as instituições não é a sua excelência, know-how em uma área de atuação ou a maestria de seu corpo docente na pesquisa em um campo específico, mas sim a eficácia quantitativa, em termos de estudantes e, por sua vez, de lucratividade, ao se ofertar determinado curso. Esse quadro concorre para a compreensão de que avaliação feita pelo Sinaes lida com CSTs que, de um lado, se constituem como uma oportunidade de negócio para as instituições privadas e, de outro, com a possibilidade de o mercado contar com uma mão de obra qualificada e mais barata, diante da existência de mais candidatos a um posto de trabalho.

\section{Considerações finais}

A discussão feita nesse artigo teve como objetivo analisar as tendências do processo de expansão e avaliação dos Cursos Superiores de Tecnologia (CSTs), no período entre 2003 e 2018, tendo como referência a política educacional formulada para o setor. Para tanto, levantou elementos para a compreensão do processo expansionista pelo qual esses 
cursos vêm passando, no Brasil, predominantemente via setor privado, após a publicação da LDB n 9.394/96. Além disso, apoiou-se na literatura da área e em análise documental sobre a implementação da política definida para a educação superior, com ênfase nas graduações tecnológicas.

Ao longo das décadas, a oferta dos CSTs passou por adequações realizadas em consonância com os marcos legais e políticos definidos para essa modalidade de graduação em cada contexto. Para Takahashi (2010), sua organização pelas Diretrizes Curriculares Nacionais (DCNs), definidas em 2002, abriu uma nova perspectiva de ingresso na educação superior, contribuindo para o aumento expressivo do número deles, bem como para minimizar o preconceito social que os rondam. Além de normatizar e organizar a oferta dos CSTs no país, essas DCNs orientaram a formação acadêmica, contemplando as dimensões teórica e prática do perfil do egresso, necessárias ao mundo do trabalho.

Frente à política educacional que os define, os CSTs cumprem os papéis que Ihes são atribuídos pelo setor produtivo, na sociedade contemporânea incrementado pelas novas tecnologias e pela força de trabalho de tecnólogos que recebem uma formação direcionada para as demandas imediatas do mercado. Nessa perspectiva, é importante que esses cursos sejam organizados visando desenvolver, de forma indissociável, habilidades profissionais e valores humanos, na direção de uma formação global e de qualidade. Dessa formação decorrem os conhecimentos, as habilidades, os valores e as atitudes que vão favorecer a inclusão social dos seus egressos no mundo do trabalho. (SMANIOTTO, 2016).

Em 2006, foi lançado o Catálogo dos CSTs -atualizado em 2010 e em 2016 -, servindo de referência para a oferta dos cursos e para os processos de avaliação, regulação e supervisão da educação tecnológica. A nomenclatura dada pelo catálogo ao expressivo conjunto de CSTs ofertados no país muito contribuiu - e vem contribuindo - para a organização das áreas desses cursos no complexo e heterogêneo campo da educação superior brasileira. Entretanto, apesar de sua relevância e singularidade, ainda apresentam certas críticas e limitações, como aquelas relacionadas ao próprio mercado de trabalho. Como apontam Campello et. al. (2009), é comum, por exemplo, os conselhos profissionais regulamentarem medidas que visem garantir a certas áreas o desempenho por profissionais egressos dos cursos de bacharelado. Ao analisar o processo de construção desse catálogo, Rocha (2009) relata que o trabalho que lhe deu origem já vinha sendo realizado há algum tempo, indicando a intenção de determinado controle sobre a oferta desses cursos, ao relacionar seu reconhecimento às denominações constantes no documento.

A partir do catálogo, os instrumentos do Sinaes foram estruturados para atender ao novo modelo institucional, com cursos mais flexíveis e rápidos, bem como às necessidades do mundo do trabalho, as quais decorrem do desenvolvimento tecnológico local e regional em determinado setor. Os avanços em relação ao rigor metodológico da avaliação desse sistema avaliativo são desafios atuais para garantir uma avaliação que assegure as especificidades dos processos de avaliação dos CSTs. A necessidade de regulação via $\mathrm{MEC} /$ Seres, em relação à organização da expansão desses cursos, pode contribuir para 
evitar que algumas IES tenham o foco pontual nos resultados da avaliação para fins de simples obtenção dos atos regulatórios, avançando para induzir a qualidade.

Apesar do aumento da oferta de CSTs por IES públicas, a iniciativa privada passou a atuar intensamente na oferta desses cursos, desde o final da década 1990 até o ano considerado nesse trabalho (2018), focando as demandas dos setores da indústria, de serviços e do mercado. Também contribuem para isso o seu reduzido tempo para a formação e a facilidade de sua expansão pela aproximação das áreas da graduação, possibilitando o aproveitamento de docentes, materiais e cenários de prática profissional.

Por fim, considerando a análise feita no artigo, ressaltamos que aquilo que continua a persistir em termos de desafios centrais apresentados aos CSTs são basicamente: (i) qualidade da formação dos tecnólogos, configurada em diferentes dimensões: docência, organização pedagógica, relação teoria e prática, intersetorialidade e empregabilidade; (ii) necessidade de seu processo expansionista acontecer sendo orientado pela qualidade e não o contrário.

\section{Referências}

ANDRADE, A. F. B. Cursos Superiores de Tecnologia: um estudo de sua demanda sob a ótica dos estudantes. 2009, 150 f. Dissertação (Mestrado em Educação). Faculdade de Educação, Universidade de Brasília, Brasília, 2009.

BERTOLIN, J. C. G. Uma proposta de indicadores de desempenho para a educação superior brasileira. Estudos em Avaliação Educacional. São Paulo, v. 22, n. 50, p. 471-490, set./dez. 2011.

BOURDIEU, Pierre. Questões de Sociologia. Lisboa: Fim de Século, 2003.

BRASIL. Decreto S/N, de 20 de outubro de 2003. Institui Grupo de Trabalho Interministerial encarregado de analisar a situação atual e apresentar plano de ação visando a reestruturação, desenvolvimento e democratização das Instituições Federais de Ensino Superior - IFES. Diário Oficial [da] República Federativa do Brasil. Brasília, DF, 21 out. 2003.

BRASIL. Lei no 10.861, de 14 de abril de 2004. Institui o Sistema Nacional de Avaliação da Educação Superior - Sinaes e dá outras providências. Diário Oficial [da] República Federativa do Brasil, Brasília, n. 72, 15 abr., Seção I, p. 3-4.

BRASIL. Lei nº 13.005, de 25 de junho de 2014. Aprova o Plano Nacional de Educação - PNE e dá outras providências. Diário Oficial [da] República Federativa do Brasil, Brasília, 26 jun., Seção I, p. 1, edição extra.

BRASIL. Lei no 9.394, de 20 de dezembro de 1996. Estabelece as diretrizes e bases da educação nacional. Diário Oficial [da] República Federativa do Brasil. Brasília: Ano CXXXIV, nº 248, 23 dez. 1996, Seção 1, p. 27.833. 
BRASIL. Lei $n^{\circ}$. 11.741, de 16 de julho de 2008a. Altera dispositivos da Lei $n^{\circ} .9 .394$, de 20 de dezembro de 1996, que estabelece as diretrizes e bases da educação nacional, para redimensionar, institucionalizar e integrar as ações da educação profissional técnica de nível médio, da educação de jovens e adultos e da educação profissional e tecnológica. Diário Oficial [da] República Federativa do Brasil. Brasília, DF, Seção 1, 17 jul. 2008, p. 5.

BRASIL. Lei $n^{\circ} .11 .892$, de 29 de dezembro de 2008b. Institui a Rede Federal de Educação Profissional e Tecnológica, e dá outras providências. Diário Oficial [da] República Federativa do Brasil. Brasília, DF, Seção 1, 30 dez. 2008, p. 1.

BRASIL. MEC. CÂMARA DE EDUCAÇÃO SUPERIOR. Parecer CNE/CES n 436, de 05 de abril de 2001. Trata dos Cursos Superiores de Tecnologia - Formação de Tecnólogos. Diário Oficial [da] República Federativa do Brasil. Brasília, DF, 6 abr. 2001. Seção 1E, p. 67.

BRASIL. MEC. Catálogo Nacional dos Cursos Superiores de Tecnologia, 2. ed. Brasília: MEC, 2010.

BRASIL. MEC. Catálogo Nacional dos Cursos Superiores de Tecnologia, 3. ed. Brasília: MEC, 2016.

BRASIL. MEC. CONSELHO NACIONAL DE EDUCAÇÃO (CNE). CONSELHO PLENO. Resolução $\mathrm{CNE} / \mathrm{CP} \mathrm{n}^{\circ} 3$, de 18 de dezembro de 2002. Institui as Diretrizes Curriculares Nacionais Gerais para a organização e o funcionamento dos cursos superiores de tecnologia. Diário Oficial [da] República Federativa do Brasil, 23 de dezembro de 2002, Seção 1, p. 162.

BRASIL. MEC. Plano de Desenvolvimento da Educação: razões, princípios e programas. Brasília: MEC, 2007. Disponível em: <http://portal.mec.gov.br/arquivos/livro/livro.pdf>. Acesso em: 10 mar. 2020

BRASIL. MEC. SECRETARIA DE EDUCAÇÃO MÉDIA E TECNOLÓGICA. Políticas públicas para a educação profissional e tecnológica. Brasília: MEC, 2004.

CAMPELLO, A. M.; ALMEIDA, A.; COSTA, L. C.; CANDEIAS, M.; DE SETAS, M. FARAH NETO, M.; RANGEL, P. V. O ensino como negócio: a expansão da oferta dos cursos de formação de tecnólogos em saúde no Brasil. Trabalho Educação e Saúde, Rio de Janeiro, vol.7, suplemento, p. 175-190, 2009.

CONFEDERAÇÃO NACIONAL DA INDÚSTRIA (CNI). Contribuição da indústria para a reforma da educação superior. Brasília: CNI/SESI/SENAI/IEL, 2004.

DOMINGOS SOBRINHO, M. Universidade Tecnológica ou Instituto Federal de Educação, Ciência e Tecnologia? Portal MEC. 2007. Disponível em: $<$ http://portal.mec.gov.br/SETEC/arquivos/pdf/uni_tec_inst_educ.pdf $>$. Acesso em 08 mar. 2020.

FAVRETTO, J.; MORETTO, C. F. Os cursos superiores de tecnologia no contexto de expansão da educação superior no Brasil: a retomada da ênfase na educação profissional. Educação \& Sociedade, Campinas, v. 34, n. 123, p. 407-424, abr.-jun. 2013. 
INSTITUTO NACIONAL DE ESTUDOS E PESQUISAS EDUCACIONAIS ANÍSIO TEIXEIRA (INEP). Resumo técnico do censo da educação superior de 2011. Brasil: INEP, 2013.

INSTITUTO NACIONAL DE ESTUDOS E PESQUISAS EDUCACIONAIS ANÍSIO TEIXEIRA (INEP). Censo da educação superior 2018. Divulgação de resultados. Brasília: INEP, 2019. Disponível

em

$<$ http://download.inep.gov.br/educacao superior/censo superior/docume ntos/2019/apresentacao_censo_superior2018.pdf> Acesso em 13 mar. 2020.

MACHADO, L. M. C. V.; MESQUITA, J. M. C. Atributos determinantes da escolha de um Curso de Graduação Tecnológica. Revista Brasileira de Gestão e Engenharia - São Gotardo/MG, Centro de Ensino Superior de São Gotardo, n. VIII jul./dez 2013, p. 29-52.

OTRANTO, C. R. Criação e implantação dos Institutos Federais de Educação, Ciência e Tecnologia - IFETs. Retta, vol. I, n. 1, p. 89-108, jan./jun. 2010.

ROCHA, M. B. Metamorfose dos cursos superiores de tecnologia no Brasil: política de acesso ao ensino superior em um estado burguês, 268f. 2009. Tese (Doutorado em Educação). Rio de Janeiro: Faculdade de Educação/Universidade Federal Fluminense, 2009.

SMANIOTTO, S. R. U. Cursos Superiores de Tecnologia: percepção de mudanças entre os alunos não tradicionais. 2006. 110f. Dissertação (Mestrado em Educação). Campinas/SP: Faculdade de Educação/ Universidade Estadual de Campinas, Campinas, 2016.

SOUSA, J. V. Educação superior no Distrito Federal: consensos, conflitos e transformações na configuração de um campo. Liber Livro/Faculdade de Educação-Universidade de Brasília, 2013.

SOUSA, J. V. Expansão e avaliação dos Cursos Superiores de Tecnologia no Brasil: tendências e controvérsias no período entre 1997 e 2015. 39a Reunião Anual da Associação Nacional De Pós-Graduação e Pesquisa em Educação (ANPEd). Anais... Niterói/RJ: Universidade Federal Fluminense, 2019, 8 p.

SOUSA, J. V. 0 ensino superior privado no Distrito Federal: uma análise de sua recente expansão: 1995-2001. 2003. 293 f. Tese (Doutorado) - Departamento de Sociologia, Universidade de Brasília, 2003.

SOUZA, J. S.; VEIGA, C. C. P. S. Determinantes sociais e políticos da regulamentação e fomento de Cursos Superiores de Tecnologia no Brasil. Revista Práxis Educacional. Vitória da Conquista - Bahia - Brasil, v. 16, n. 38 , p. 461- 482, jan./mar. 2020.

TAKAHASHI, A. R. W. Cursos superiores de tecnologia em gestão: reflexões e implicações da expansão de uma (nova) modalidade de ensino superior em administração no Brasil. Revista de Administração Pública, v. 44, n. 2, p. 385-414, 2010.

TAKAHASHI, A. R. W.; AMORIM, W. A. C. Reformulação e expansão dos cursos superiores de tecnologia no Brasil: as dificuldades da retomada da educação profissional. Ensaio: Avaliação e Políticas Públicas em Educação. vol. 16, n.59, p.207-228, set./dez. 2008. 


\section{Informações sobre 0 autor:}

\section{José Vieira de Sousa}

Doutor em Sociologia pela Universidade de Brasília (UnB). Atua como professor associado da UnB. É membro do Conselho Científico do Fórum da Gestão do Ensino Superior nos Países e Regiões de Língua Portuguesa (FORGES); é líder do Grupo de Estudos de Políticas de Avaliação da Educação Superior (GEPAES) no Diretório de Grupos de Pesquisa do Brasil/CNPq, é membro do Conselho Editorial do periódico Revista Linhas Críticas (UnB); é Avaliador Institucional e de cursos de graduação do Banco BASIS do Instituto Nacional de Estudos e Pesquisas Educacionais Anísio Teixeira (INEP).

ORCID iD: http://orcid.org/0000-0002-6948-1549

E-mail: sovieira1@gmail.com 